\title{
Supercritical Fluid Phase Separations Induced by Chemical Reactions
}

\author{
F.H. Ree \\ J.A. Viecelli \\ M. van Thiel
}

This paper was prepared for submittal to the

Materials Research Society 1997 Fall Meeting

Boston, MA

December 1-5, 1997

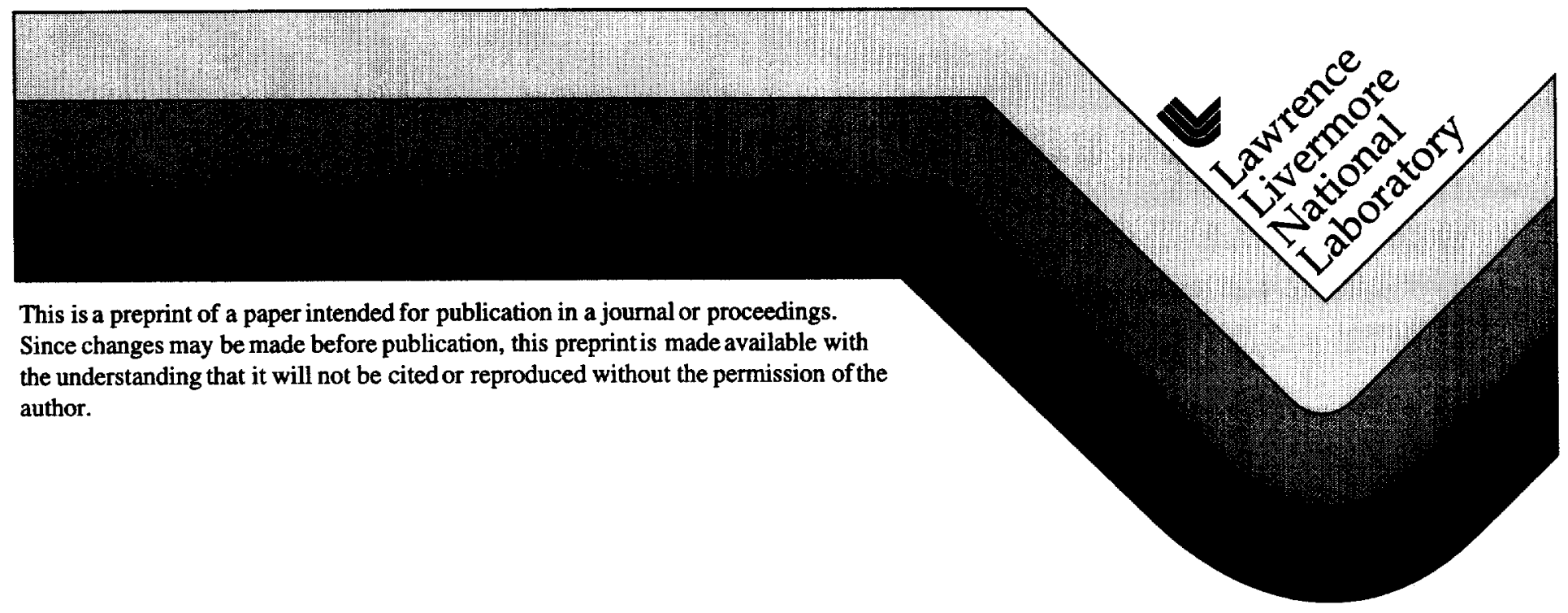




\section{DISCLAIMER}

This document was prepared as an account of work sponsored by an agency of the United States Government. Neither the United States Government nor the University of California nor any of their employees, makes any warranty, express or implied, or assumes any legal liability or responsibility for the accuracy, completeness, or usefulness of any information, apparatus, product, or process disclosed, or represents that its use would not infringe privately owned rights. Reference herein to any specific commercial product, process, or service by trade name, trademark, manufacturer, or otherwise, does not necessarily constitute or imply its endorsement, recommendation, or favoring by the United States Government or the University of California. The views and opinions of authors expressed herein do not necessarily state or reflect those of the United States Government or the University of California, and shall not be used for advertising or product endorsement purposes. 


\section{UCU JC 12785 \\ SUPERCRITICAL FLUID PHASE SEPARATIONS INDUCED BY CHEMICAL REACTIONS}

Francis H. Ree, James A. Viecelli, and Mathias van Thiel

Lawrence Livermore National Laboratory, Livermore, CA 94550

ABSTRACT

Our statistical mechanical studies predict that a chemically reactive system containing species composed of $\mathrm{C}, \mathrm{H}, \mathrm{N}, \mathrm{O}$ atoms can exhibit a phase separation into a $\mathrm{N}_{2}$-rich and a $\mathrm{N}_{2}$-poor phase. The preset work is concerned with the effect of the fluid phase separation upon addition of $\mathrm{F}$ atoms in the system. Our study shows that $\mathrm{F}$ atoms mainly appear as a constituent of $\mathrm{HF}$ in a $\mathrm{N}_{2}$-poor fluid phase up to a certain pressure beyond which they occur as $\mathrm{CF}_{4}$ in a $\mathrm{N}_{2}$-rich phase and that the phase separation may be abrupt in thermodynamic sense. The pressure at the phase boundary can occur at about $30 \mathrm{GPa}$ at $3000 \mathrm{~K}$ and about $10 \mathrm{GPa}$ to $20 \mathrm{GPa}$ at $1000 \mathrm{~K}$. Some of these ranges may be accessible by present-day experimental high-pressure techniques. We discuss implications of this study to detonation physics.

\section{INTRODUCTION}

Currently available studies on supercritical fluid phase separations are limited to chemically nonreactive systems. The present study is concerned with possible influence of chemical reactions on such a phase change at high pressure $(\mathrm{P})$ and high temperature $(T)$. Such a study is important to a reliable prediction of the performance of high explosives. High explosives molecules are mainly composed of $\mathrm{C}, \mathrm{H}, \mathrm{N}, \mathrm{O}$ atoms. Their detonation produces a mixture of many species such as $\mathrm{N}_{2}, \mathrm{CO}_{2}, \mathrm{CO}, \mathrm{H}_{2} \mathrm{O}$, and condensed carbon plus minor amounts of $\mathrm{H}_{2}, \mathrm{NH}_{3}$, $\mathrm{O}_{2}$, NO, etc. Hence, we use high explosives at $\mathrm{P}=1$ to $100 \mathrm{GPa}$ and $\mathrm{T}=100$ to $5000 \mathrm{~K}$ as the chemically reactive systems to examine a possible supercritical fluid phase separation and its effect on post-detonation product mixtures.

In this regard we have earlier used the statistical mechanical chemical equilibrium (CHEQ) code $^{1}$ to investigate the occurrence of supercritical fluid phase separations in binary and ternary mixtures of $\mathrm{N}_{2}, \mathrm{CO}_{2}$, and $\mathrm{H}_{2} \mathrm{O}$ molecules and in detonation products of a condensed explosive, PBX-9404. ${ }^{2}$ The most significant result of our analysis was that the $\mathrm{N}_{2}-\mathrm{H}_{2} \mathrm{O}$ system may exhibit a supercritical fluid phase separation in the same (T, $P$ ) range as we encounter in explosives experiments. This prediction has been validated by diamond-anvil-cell experiments up to $P$ less than $3 \mathrm{GPa}$ and $\mathrm{T}$ less than $1000 \mathrm{~K}$. ${ }^{2}$ The most significant practical result of such a prediction for explosives is that, by incorporating the $\mathrm{N}_{2}$-fluid phase separation in modeling the detonation of high explosives, we obtain better agreement with the experimental detonation data.

Most modern high explosives are "composites" with two main components; explosive molecules and organic binders to hold, mold, and pack the explosive powders. Recently, binders containing fluorine atoms are drawing interest for the safety reason. Typical ones are Kel-F with polymeric composition $\left(\mathrm{C}_{8} \mathrm{H}_{2} \mathrm{Cl}_{3} \mathrm{~F}_{11}\right)_{\mathrm{n}}$ and viton $\mathrm{A}$ with composition $\left(\mathrm{C}_{5} \mathrm{H}_{3.5} \mathrm{~F}_{6.5}\right)_{\mathrm{n}}$. LX-17 uses the KelF binder to mold high explosive, TATB $\left(=\mathrm{C}_{6} \mathrm{H}_{6} \mathrm{~N}_{6} \mathrm{O}_{6}\right)$, while $\mathrm{LX}-04$ uses the viton $\mathrm{A}$ binder to mold $\mathrm{HMX}\left(=\mathrm{C}_{4} \mathrm{H}_{8} \mathrm{~N}_{8} \mathrm{O}_{8}\right)$. The former is insensitive and the latter more sensitive. Results presented below show that the fluorine chemistry can critically influence the supercritical 
fluid phase separation between the $\mathrm{N}_{2}$-rich and the $\mathrm{N}_{2}$-poor phases in detonation product mixtures and that it in turn affects the detonation properties of LX-17 and LX-04.

\section{FORMULATION}

Theory

$\mathrm{LX}-17$ is a composite explosive with $\mathrm{C}_{2.29} \mathrm{H}_{2.18} \mathrm{~N}_{2.15} \mathrm{O}_{2.15} \mathrm{~F}_{0.2} \mathrm{Cl}_{0.054}$ per $100 \mathrm{~g}$, while $100 \mathrm{~g}$ of $\mathrm{LX}-04$ is represented by $\mathrm{C}_{1.55} \mathrm{H}_{2.58} \mathrm{~N}_{2.30} \mathrm{O}_{2.30} \mathrm{~F}_{0.52}$. The amount of $\mathrm{Cl}$ in $\mathrm{LX}-17$ is small and will be neglected in the present work. We assume that these explosives produce gaseous species $\left(\mathrm{N}_{2}\right.$, $\mathrm{CO}_{2}, \mathrm{CO}, \mathrm{H}_{2} \mathrm{O}, \mathrm{H}_{2}, \mathrm{NH}_{3}, \mathrm{O}_{2}, \mathrm{NO}$, etc.) and condensed carbon in a graphite, diamond, or liquid phase. The Gibbs free energy of this heterogeneous system can be obtained as a sum of the Gibbs free energies for the gaseous mixture phase and the condensed carbon phases. The Gibbs free energy for carbon has been discussed in detail and will not be repeated here. ${ }^{3}$ We sketch below only the pertinent portions of the fluid-phase Gibbs free energy.

We use exp- 6 potentials to represent interactions between $a(i, j)$ pair of detonation product species in a fluid mixture;

$$
\phi_{i j}=\frac{\varepsilon_{i j}}{\alpha_{i j}-6}\left\{6 \exp \left[\alpha_{i j}\left(1-\mathrm{r} / \mathrm{r}_{i j}^{*}\right)\right]-\alpha\left(\mathrm{r}_{i j}^{*} / \mathrm{r}\right)^{6}\right\} .
$$

For polar molecules such as $\mathrm{H}_{2} \mathrm{O}$ and $\mathrm{HF}$, the well depth $\varepsilon$ is made temperature dependent by introducing an additional parameter $\lambda$,

$$
\varepsilon=\varepsilon_{0}(1+\lambda / T),
$$

which describes the increasingly attractive hydrogen-bonding character of the interaction as the temperature decreases.

Mixture systems will be described by using the improved van der Waals one-fluid model. ${ }^{4}$ It assumes that all molecules in mixtures are identical and interact with an effective exp- 6 potential whose parameters depend on the mole fractions $\left\{x_{i}\right\}$ and $\left(\alpha, \varepsilon, \mathrm{r}^{*}\right)$ parameters of individual pair interactions as follows:

$$
\begin{aligned}
& \left(r^{*}\right)^{3}=\sum x_{i} x_{j}\left(\mathrm{r}_{\mathrm{ij}}^{*}\right)^{3}, \\
& \varepsilon=\sum x_{i} x_{j} \varepsilon_{i j}\left(r_{i j}^{*} / r^{*}\right)^{3}, \\
& \alpha=\sum x_{i} x_{j} \alpha_{i j} \frac{\varepsilon_{i j}\left(r_{i j}^{*}\right)^{3}}{\varepsilon\left(r^{*}\right)^{3}} .
\end{aligned}
$$

The improved van der Waals one-fluid model has been verified with Monte Carlo simulations. ${ }^{4}$

Parameters $\alpha, \varepsilon$, and $\mathrm{r}^{*}$ in Eq. (1) for like-pair species $(\mathrm{i}=\mathrm{j})$ are mostly obtained by matching shock wave data or from various theoretical methods. Parameters $\alpha, \varepsilon$, and $\mathrm{r}^{*}$ for unlike-pair interactions $(i \neq j)$ are derived from the generalized Lorentz-Berthelot equations, ${ }^{1}$

$$
\varepsilon_{i j}=k_{i} \sqrt{\varepsilon_{i i} \varepsilon_{j j}} ; \mathrm{r}_{i j}^{*}=\frac{1}{2} l_{\mathrm{ij}}\left(r_{i i}^{*}+\mathrm{r}_{\mathrm{jj}}^{*}\right) ; \alpha_{i j}=m_{i j} \sqrt{\alpha_{i i} \alpha_{j j}} \text {, }
$$


by using $\left(\alpha, \varepsilon, \mathrm{r}^{*}\right)$ parameters for the homo-molecular interactions $(\mathrm{i}=\mathrm{j})$ and by modifying $\left(k_{i j}\right.$, $l_{i j}, m_{i j}$ ) parameters, originally set equal to 1 , if there is suitable data to do so.

We compute the Helmhotlz free energy (hence, the Gibbs free energy) of the fluid-phase mixture system by using the effective one-component potential [Eqs. (1) - (4)] in the Ross variational theory which is an improved version of Mansoori's original hard-sphere variational theory. The Ross theory shows excellent agreement with computer simulation data for a wide variety of potentials that include the exp-6 form.

The above mathematical formulations are programmed into the CHEQ code. The CHEQ code solves for $\left\{x_{i}\right\}$ by minimizing the Gibbs free energy of the entire heterogeneous mixture system (containing fluid mixtures and condensed phase carbon) and computes thermodynamic quantities by taking appropriate numerical derivatives of the free energy.

\section{$\underline{\text { HF-HF intermolecular potential }}$}

Detonation of LX-17 and LX-04 produces hydrogen fluoride (HF). Hence, explosive performance prediction requires information on intermolecular pair potentials with HF. However, experimental data (e.g., shock wave) on HF needed for the present work do not exist because of its corrosive nature. Furthermore, HF is a strongly hydrogen bonding system, which, in spite of its simplicity, makes predicting its intermolecular potential difficult. We describe below our attempt to obtain the HF pair potentials based on available information.

We use the structure of condensed HF at low temperatures as a guide. HF molecules have a hydrogen bond strength of about $0.3 \mathrm{eV}$ and form chain- and ring-clusters in the gas and liquid phases. The crystals structure of $\mathrm{HF}$ is orthorhombic with space group $C_{2 v}^{12}$. It consists of zigzag hydrogen bonded F-F chains that are parallel to the [100] plane. The F-F bond distance in the chain is $2.49 \AA$ at $148 \mathrm{~K}$ and the nearest neighbor inter-chain distances are 3.12 to $3.20 \AA$.

We have examined several quantum mechanical and semiempirical HF-HF potentials which are consistent with the inter- and intra-chain distances of the crystal structure by representing them by an exponential- 6 potential. One of them (hereafter, referred to as $\mathrm{HFb}$ ) has a minimum value at $\mathrm{r}^{*}(=2.95 \AA)<\mathrm{r}_{\mathrm{e}}=3.12 \AA$ (= the smallest inter-chain F-F distance) was obtained by fitting the parameters to the detonation velocity of a high explosive $1,2 \mathrm{DP}\left(\mathrm{C}_{3} \mathrm{H}_{6} \mathrm{~N}_{2} \mathrm{~F}_{2}\right)$. But it gave inconsistent detonation velocities of some other explosives, i.e., FEFO $\left(\mathrm{C}_{5} \mathrm{H}_{6} \mathrm{~N}_{4} \mathrm{O}_{10} \mathrm{~F}_{2}\right)$, FM1 $\left(\mathrm{C}_{1.906} \mathrm{H}_{2.872} \mathrm{~N}_{1.265} \mathrm{O}_{3.164} \mathrm{~F}_{0.308}\right), \mathrm{PF}\left(\mathrm{C}_{6} \mathrm{H}_{2} \mathrm{~N}_{3} \mathrm{O}_{6} \mathrm{~F}_{1}\right)$, and LX-17. The best available potential (referred to as $\mathrm{HFa}$ ) was obtained by spherically averaging the ab initio data of Barton and Howard weighted by a Boltzman factor. ${ }^{6}$ Numerical values of the potential $\mathrm{HFa}$ and $\mathrm{HFb}$ are:

HFa: $\mathcal{E} / \mathrm{k}=188.6 \mathrm{~K}, \mathrm{r}^{*}=3.19 \AA, \alpha=13.01, \lambda=368.6 \mathrm{~K}$, $\mathrm{HFb}: \varepsilon / \mathrm{k}=188.6 \mathrm{~K}, \mathrm{r}^{*}=2.95 \AA, \alpha=13.01, \lambda=368.6 \mathrm{~K}$,

Note that the potential minimum $\left(\mathrm{r}^{*}=3.19 \AA\right)$ of $\mathrm{HFa}$ is close to $\mathrm{r}_{\mathrm{e}}$. The differences in the calculated detonation velocities $\left(\mathrm{D}_{\mathrm{CJ}}\right)$ between the $\mathrm{HFa}$ and $\mathrm{HFb}$ potentials are about $2.5 \%$ for FEFO and LX-04. These are still significant differences, since uncertainties in many experimental $\mathrm{D}_{\mathrm{CJ}}$ are usually within $1 \%$. Table 1 shows two sets of unlike pair potential parameters that fine 
tune the interactions $\mathrm{HFa}-\mathrm{X}\left(\mathrm{X} \equiv \mathrm{CO}, \mathrm{CO}_{2}, \mathrm{H}_{2} \mathrm{O}\right)$ for two sets of experimental data. The present work shows that accurate knowledge of the HF interaction potential as well as good experiments is critical to the $\mathrm{HE}$ performance prediction.

Table 1. Lorentz-Berthelot correction factors, Eq. (4), for unlike-pair interaction constants..

\begin{tabular}{|c|c|c|c|c|c|c|}
\hline \multirow[b]{2}{*}{ Correction factors } & \multicolumn{3}{|c|}{ Set A } & \multicolumn{3}{|c|}{ Set B } \\
\hline & $k$ & $l$ & $m$ & $k$ & $l$ & $m$ \\
\hline $\mathrm{H}_{2} \mathrm{O}-\mathrm{HF}$ & 1.0 & 1.101 & 1.0 & 1.0 & 0.976 & 1.0 \\
\hline $\mathrm{CO}_{2}-\mathrm{HF}$ & 1.0 & 0.841 & 1.0 & 1.0 & 1.095 & 1.0 \\
\hline $\mathrm{CO}-\mathrm{HF}$ & 1.0 & 1.0 & 1.0 & 1.0 & 1.080 & 1.0 \\
\hline
\end{tabular}

Influence of fluorine chemistry

As mentioned earlier, our statistical mechanical calculations revealed that post-detonation mixtures containing $\mathrm{C}, \mathrm{N}, \mathrm{H}, \mathrm{O}$ atoms separate into an $\mathrm{N}_{2}$-rich and an $\mathrm{N}_{2}$-poor fluid phases near or above the $\mathrm{CJ}$ point. In addition, $\mathrm{F}$ atoms in $\mathrm{Kel}-\mathrm{F}$ or viton $\mathrm{A}$ binder react with $\mathrm{H}$ or $\mathrm{C}$ atoms

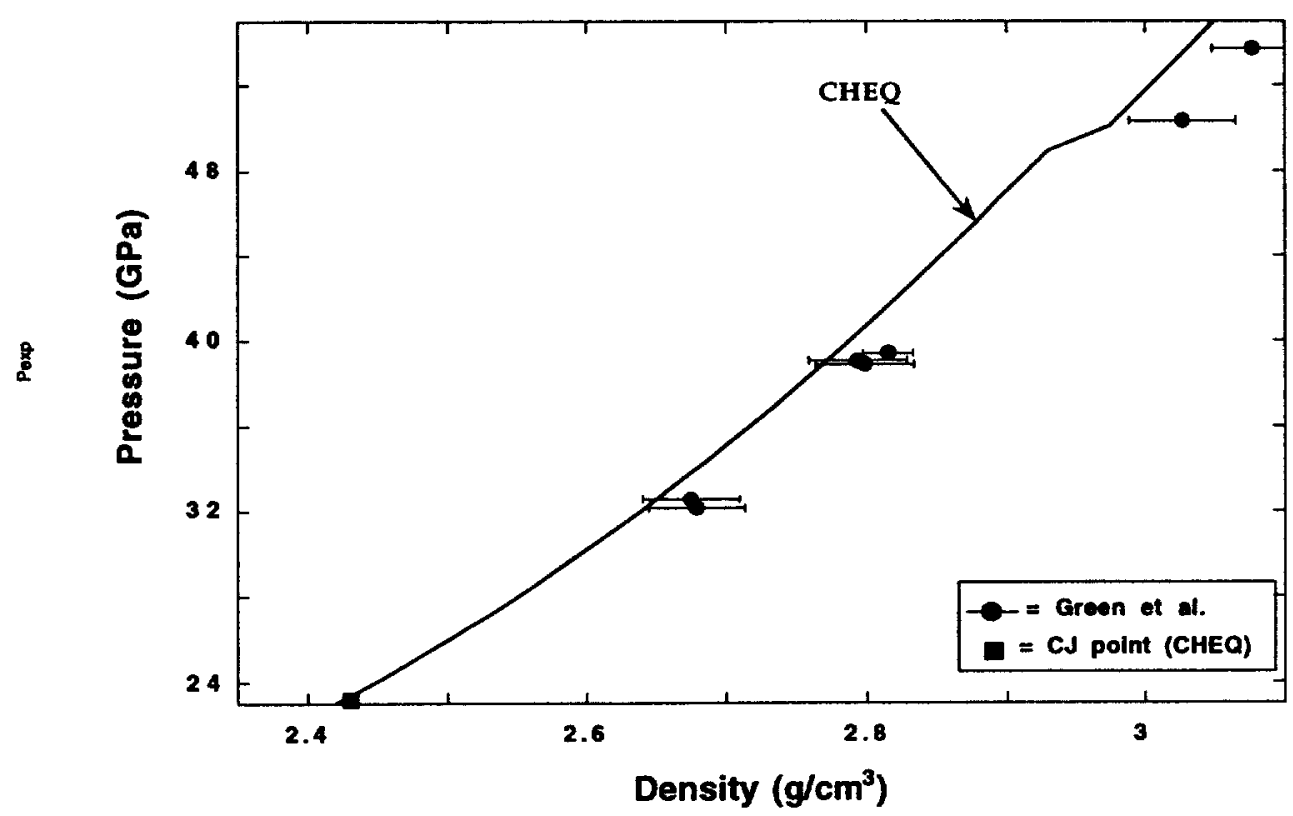

Figure 1. Hugoniots of LX-17 using the HFa parameters for the HF-HF potential and Set $A$ for unlike-pair potentials, and assuming that it burns $96.5 \%$ of the original sample. Also shown are: experimental data of Green et al. in Ref. 7.

to produce $\mathrm{HF}$ and $\mathrm{CF}_{4}$. Here we need to be concerned with a possible influence of chemical reactions involving these additional species on the $\mathrm{N}_{2}$-rich and an $\mathrm{N}_{2}$-poor phases. Such calculations are carried out here for LX-17 and LX-04.

Figure 1 shows the Hugoniot of LX-17 based on CHEQ, assuming that the HE burns $96.5 \%$ which reflects the fact that $\mathrm{LX}-17$ is very insensitive and has significant detonation kinetics effects. The calculation uses the HFa for the HF-HF potential and Set A (in Table 1) for the HF$\mathrm{X}$ set. The Hugoniot shows a 'kink' near $50 \mathrm{GPa}$. This is attributed to the fluorine chemistry which drastically complicates the previously known phase separation between the $\mathrm{N}_{2}$-rich and 
$\mathrm{N}_{2}$-poor phases. Namely, up to about $50 \mathrm{GPa}, \mathrm{F}$ atoms prefer to form $\mathrm{HF}$ molecules and occur in the $\mathrm{N}_{2}$-poor phase, which contains mostly $\mathrm{H}_{2} \mathrm{O}$ molecules. As $\mathrm{HF}$ and $\mathrm{H}_{2} \mathrm{O}$ are the two strongest hydrogen-bonding molecules, they prefer to associate with each other. However, above $50 \mathrm{GPa}$, $\mathrm{F}$ atoms form $\mathrm{CF}_{4}$ molecules in the $\mathrm{N}_{2}$-rich phase. Namely, high pressure forces $\mathrm{F}$ atoms to be in a more compact configuration to lower the free energy of the mixture (Le Chaterlier's principle). The 'softening' of the Hugoniot by the shift, $\mathrm{HF}(\alpha) \rightarrow \mathrm{CF}_{4}(\beta)$, is seen to bring the calculation closer to experiment. ${ }^{7}$

In Fig. 2 we examine this shift in fluorine chemistry in detail by comparing the mole fractions ( $=$ moles/total number of moles in a given phase) of $\mathrm{N}_{2}, \mathrm{H}_{2} \mathrm{O}, \mathrm{HF}$, and $\mathrm{CF}_{4}$ along the $0.5-\mathrm{eV}$ isotherm of $\mathrm{LX}-04$. We note that the addition of $\mathrm{F}$ atoms produces three different characteristics to the $\mathrm{N}_{2}$-rich and an $\mathrm{N}_{2}$-poor phases at different levels of pressures, $\mathrm{P}_{1}<\mathrm{P}_{2}<\mathrm{P}_{3}$.

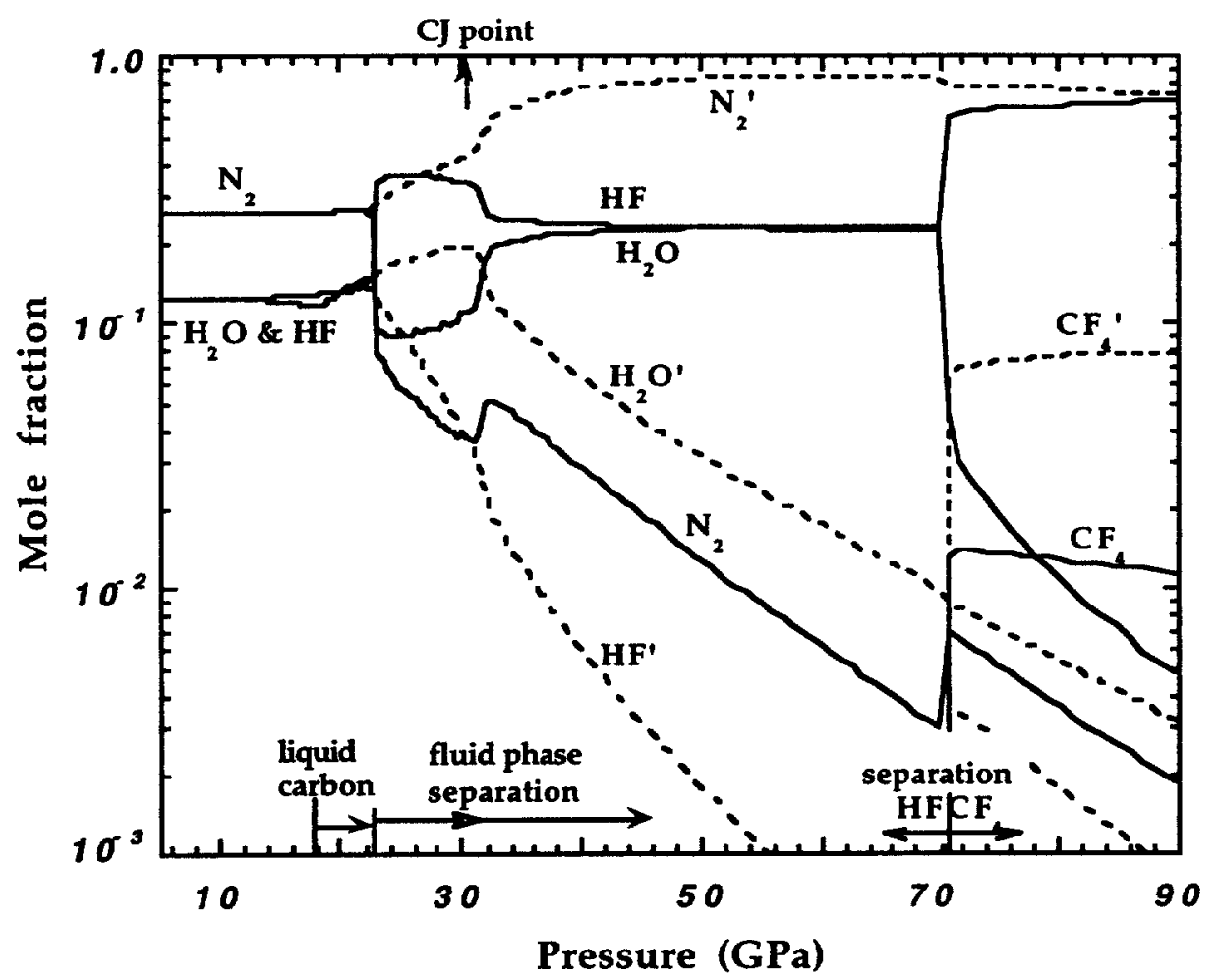

Figure 2. Mole fractions of detonation products along the $0.5 \mathrm{eV}$ isotherm of $\mathrm{LX}-04$, based on the HFa parameters for the HF-HF potential and Set A for unlike-pair potentials: solid line $=$ Phase $\alpha$ and dashed line $=$ Phase $\beta$.

First, within a small pressure interval $\left(\mathrm{P}_{1}, \mathrm{P}_{2}\right)$ indicated by an open arrow at $\mathrm{P}=30 \mathrm{GPa}$ in Fig. 2, fluid mixtures separate into Phases $\alpha$ and $\beta$, in which Phase $\alpha$ is rich in HF and Phase $\beta$ is rich in both $\mathrm{N}_{2}$ and $\mathrm{H}_{2} \mathrm{O}$. At the next pressure interval, $\mathrm{P}_{2}<\mathrm{P}<\mathrm{P}_{3}, \mathrm{H}_{2} \mathrm{O}$ molecules in Phase $\beta$ gradually change their phase preference to Phase $\alpha$ so that they can be close to similar hydrogen-bonding molecules, HF. At the third pressure interval, $\mathrm{P}>\mathrm{P}_{3}, \mathrm{HF}$ molecules in Phase $\alpha$ become thermodynamically less stable with respect to formation of $\mathrm{CF}_{4}$ molecules, which prefer to be in Phase $\beta$, associated with the $\mathrm{N}_{2}$-rich phase. This last phase separation occurs at pressure $P_{3}$ which is well above $P_{1}$ and is abrupt in thermodynamic sense. 
Examination of Fig. 2 shows that this phase separation involves the formation of diamond through a chemical reaction,

$$
2 \mathrm{CO}(\beta)+4 \mathrm{HF}(\alpha) \rightarrow \mathrm{CF}_{4}(\beta)+2 \mathrm{H}_{2} \mathrm{O}(\alpha)+\mathrm{C} \text { (diamond). }
$$

The pressure $\mathrm{P}_{3}$ at the third phase boundary can be as low as about $10 \mathrm{GPa}$ to $20 \mathrm{GPa}$ at $1000 \mathrm{~K}$. These ranges should be accessible to present-day experimental high-pressure techniques; hence, it will be worthwhile to experimentally confirm the prediction made here.

However, it should be noted that this shift in fluorine chemistry is extremely delicate and sensitive to unlike pair potentials between $\mathrm{HF}$ and other species. For example, if Set B is used instead of Set $A$, the shift in fluorine chemistry, $\mathrm{HF}(\alpha) \rightarrow \mathrm{CF}_{4}(\beta)$, coincides with the pressure $\left(\mathrm{P}_{1}\right)$ where the $\mathrm{N}_{2}$-rich fluid phase separation occurs at first and no additional change in the character of the fluid phase separation is predicted at higher pressures.

\section{SUMMARY}

The present nonempirical calculations show that addition of a small amount of fluorine can drastically alter the supercritical fluid phase separation in a system with $\mathrm{C}, \mathrm{H}, \mathrm{N}, \mathrm{O}$ atoms. A small change in unlike-pair interaction parameters between $\mathrm{HF}$ and other chemical species can lead to the first order fluid phase separation involving the shift in fluorine chemistry, $\mathrm{HF}(\alpha) \rightarrow$ $\mathrm{CF}_{4}(\beta)$. Detonation properties of high explosives such as LX-17 and LX-04 are sensitive to such a fluid phase separation. Moreover, these changes are predicted to occur in the pressure and temperature regime accessible by the diamond-anvil-cell technology. Such an experiment will provide an accurate way of determining the unlike-pair potential parameters involving $\mathrm{HF}$ molecules.

\section{ACKNOWLEDGMENTS}

This work was done under the auspices of the US Department of Energy by the Lawrence Livermore National Laboratory under contract number W-7405-ENG-48. We thank Dr. Yim Lee for his contributions to the work on LX-04 discussed in this paper.

\section{REFERENCES}

1. F. H. Ree, J. Chem. Phys. 81, 1251 (1984); 84, 5845 (1986).

2. M. Costantino and S. F. Rice, J. Phys. Chem. 95,9034 (1991).

3. F. H. Ree and M. Van Thiel, High Pressure Research 10, 607 (1992); also see references quoted therein.

4. F. H. Ree, J. Chem. Phys. 78, 409 (1983).

5. M. Ross, J. Chem. Phys. 71, 1567 (1979).

6. F. H. Ree and D. F. Calef, in Shock Compression of Condensed Matter-1989, edited by S. C. Schmidt, J. N. Johnson, and L. W. Davison (Elsevier Science, NY, 1990), p. 91.

7. L. Green, E. Lee, A. Mitchell, and C. Tarver, in Proc. Eighth Symposium (International) on Detonation, Albuquerque, NM July 1985, NSWC MP 86-194, (Naval Surface Weapons Center, White Oak, Silver Spring, MD 20903-5000, 1986) p. 587. 


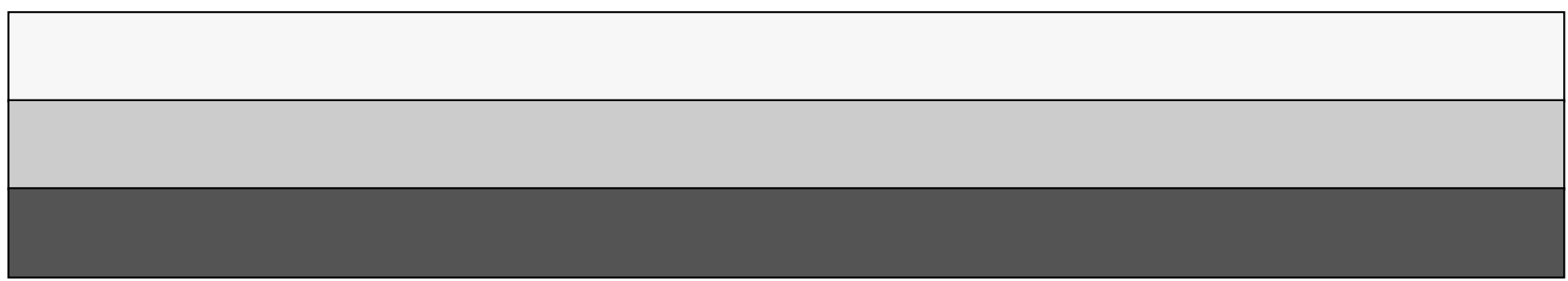

